\title{
Testicular torsion and low relative humidity in a tropical country
}

\author{
O A MABOGUNJE
}

\section{Abstract}

One hundred and thirty one patients with testicular torsion were reviewed retrospectively to investigate the association of testicular torsion with air temperature and low relative humidity in Zaria, Nigeria. The incidence of testicular torsion was significantly increased during the harmattan season (November to February), when relative humidity is low and temperature decreased. Relative humidity was more closely correlated with the incidence of testicular torsion than was air temperature.

Testicular torsion is a major contributor to male infertility in Zaria, and further study of its causes is required.

\section{Introduction}

The aetiology of testicular torsion is uncertain, although Shukla et al described an association between testicular torsion and cold weather in Dublin. ${ }^{1}$ Such an association was also confirmed in Bristol but not in Calgary, where there are greater extremes of daily temperature than in the United Kingdom. ${ }^{2}{ }^{3}$

This paper reports the association of testicular torsion with low relative humidity in Zaria, Nigeria.

\section{Patients, methods, and results}

From 1972 to 1984 scrotal exploration was performed in 192 patients who presented to this hospital with pain of the scrotum. Testicular torsion was confirmed in 131. I studied this consecutive series of patients with testicular torsion retrospectively. Only three were younger than 10 , but $80 \%$ were aged 11-25.

The month in which the episode of torsion leading to scrotal exploration occurred was obtained from the clinical notes for each patient. The mean daily relative humidity and the mean daily temperatures for each month were obtained from the record of meteorological observations at the Institute

\section{Department of Surgery, Ahmadu Bello University Hospital, Zaria,} Nigeria

O A MABOGUNJE, MD, FMCS, professor of surgery of Agricultural Research in Zaria. The figure shows the distribution of cases by month with the corresponding meteorological data. The incidence of testicular torsion increased during the harmattan season, when relative humidity is low and air temperature decreased.

The data were analysed statistically using Edward's test for seasonality 4 this yielded $\chi^{2}=19 \cdot 93,2 \mathrm{df}, \mathrm{p}<0 \cdot 001$. Furthermore, Spearman's rank correlation of the number of cases with relative humidity yielded $\mathrm{r}=-0.52$, $\mathrm{p}<0.05$, and with temperature $\mathrm{r}=-0.47,0.05<\mathrm{p}<0.1$. Thus the low relative humidity appeared to have a greater influence on the incidence of testicular torsion than the decreased temperature.

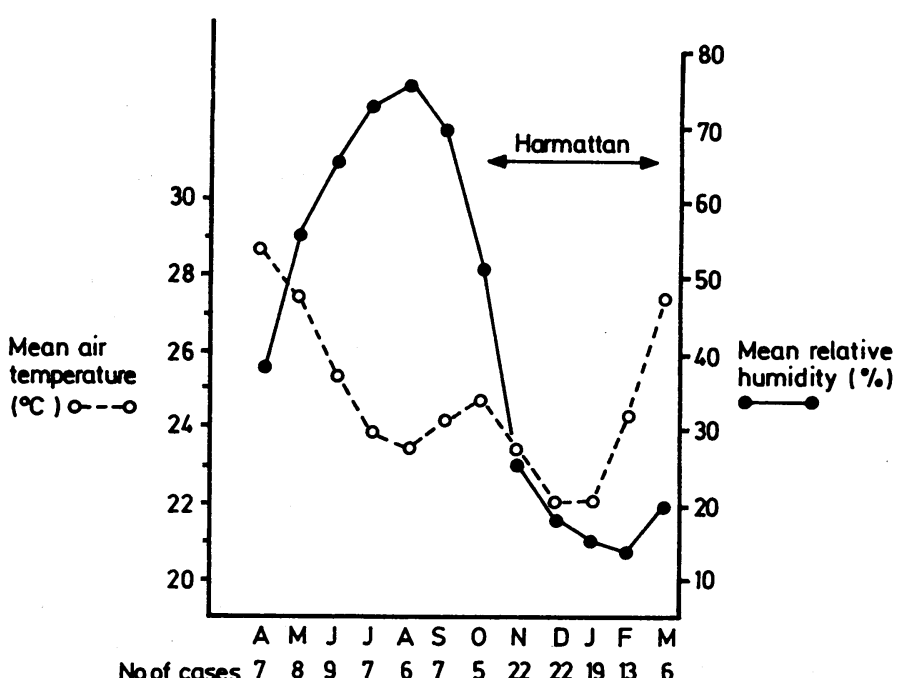

Mean monthly temperatures throughout $1938-80$ and relative humidity throughout 1954-80 in relation to total number of cases for each month during 1972-84.

\section{Discussion}

Assuming a uniform monthly incidence of testicular torsion, a cumulative total of 11 cases each month would be expected. The monthly totals during the harmattan months (November to February), however, varied from 13 to 22 , while the totals during the warm and wet months (March to October) varied from five to nine. 
This observation has not been previously reported, and as yet there is no satisfactory explanation for it.

During the harmattan season evaporative water loss is increased because of the low relative humidity. The latent heat lost from the body causes a feeling of cold, and shivering may occur. Cold can cause a reflex retraction of the testis, as seen in patients whose testes retract when an examiner's hands are cold. Anatomical variations such as the bell clapper anomaly, a long mesorchium, and a separated epididymis have been described in patients undergoing surgery for testicular torsion. In such patients reflex contraction of the testicular capsule, dartos, or cremasteric muscle has been postulated to be the mechanism initiating torsion. ${ }^{1}$

In both winter and harmattan people wear more clothes to keep warm. Might the amount of clothing worn be related to the torque that causes the retracting testis to undergo torsion? Toddlers and infants in this rural community traditionally do not wear nappies, which might perhaps account for the paucity of young children in this series.
Whatever the cause of testicular torsion, the condition accounts for $11 \%$ of all orchidectomies in Zaria and is, therefore, an important contributor to male infertility.

I thank the director, Institute of Agricultural Research, Ahmadu Bello University, Zaria, for the meteorological data and Dr P Singha for performing the statistical analyses.

\section{References}

1 Shukla RB, Kelly DG, Daly L, Guiney EJ. Association of cold weather with testicular torsion. $\mathrm{Br}$ Med f 1982;285:1459-60.

Williamson R. Cold weather and testicular torsion. Br Med f 1983;286:1436.

2 Williamson R. Cold weather and testicular torsion. Br Med J 1983;286:1436.

3 Preshaw RM. Seasonal frequency of testicular torsion. Can J Surg 1984;27:404-5.

4 Edwards JH. The recognition and estimation of cyclic trends. Ann Hum Genet 1961;25:83-7.
5 Mabogunje OA, Grundy DJ, Lawrie JH. Orchidectomy in a rural African population. Trans $R$ So Mabogunje OA, Grundy DJ, Law
Trop Med Hyg 1980;74:749-51.

(Accepted 30 August 1985)

\title{
Vagal slowing of the heart during haemorrhage: observations from 20 consecutive hypotensive patients
}

\author{
K SANDER-JENSEN， $\mathrm{N}$ H SECHER， P BIE， J WARBERG， T W SCHWARTZ
}

\begin{abstract}
Heart rate and arterial blood pressure were monitored in 20 consecutive patients during resuscitation from haemorrhagic shock. The mean blood loss $(2 \cdot 3$ (SEM 0.3) 1) corresponded to $36(4) \%$ of their estimated mean blood volume. During shock the mean blood pressure was $81 / 55(3 / 2) \mathrm{mm} \mathrm{Hg}$ and heart rate 73 (3) beats $/ \mathrm{min}$. Administration of blood and crystalloids resulted in immediate increases to $111 / 72(2 / 2) \mathrm{mm} \mathrm{Hg}$ and $102(3)$ beats $/ \mathrm{min}$ followed by steady state values of $131 / 79$ (6/3) $\mathrm{mm} \mathrm{Hg}$ and 82 (2) beats/min. In three otherwise healthy patients plasma concentrations of the vagally regulated hormone pancreatic polypeptide rose from resting values of $64-77 \mathrm{pmol} / 1(272-327 \mathrm{pg} / \mathrm{ml})$ to $198-280 \mathrm{pmol} / \mathrm{l}(842-1190 \mathrm{pg} / \mathrm{ml})$.
\end{abstract}

These findings suggest that reversible hypotensive hypovolaemic shock is characterised by a decrease in heart rate conceivably reflecting an increase in vagal tone.

\footnotetext{
Departments of Surgery A and Anaesthesia, Glostrup Hospital, DK-2600 Glostrup, Denmark

K SANDER-JENSEN, MD, research fellow

N H SECHER, MD, PHD, senior registrar in anaesthesia

Department of Medical Physiology C, Panum Institute, DK-2200 Copenhagen $\mathbf{N}$, Denmark

P BIE, MD, PHD, associate professor

J WARBERG, MD, PHD, associate professor

Department of Clinical Chemistry, Rigshospitalet, DK-2100 Copenhagen $\emptyset$, Denmark

T W SCHWARTZ, MD, PHD, MRC professor

Correspondence to: Dr Kåre Sander-Jensen, Department of Medical Physiology C, Panum Institute, DK-2200 Copenhagen N, Denmark.
}

\section{Introduction}

Circulatory homoeostasis is dependent on the intravascular volume and its distribution. Redistribution of the blood volume induced by head up tilt (reverse Trendelenburg's position), lower body negative pressure, and venous congestion of the legs during constriction by pneumatic cuffs is associated with tachycardia and vasoconstriction provided that blood pressure is maintained. A moderate increase in heart rate to $80-90$ beats/min (certainly below 130 beats $/ \mathrm{min}$ ) is typical. ${ }^{1}$ During progressive central hypovolaemia circulatory control is suddenly changed. Blood pressure and heart rate decrease concomitantly with a decrease in total peripheral resistance, and syncope and nausea may occur. These manifestations of severe central hypovolaemia also occur during induced haemorrhage. ${ }^{23}$ Yet in current textbooks the "vasovagal" reaction to bleeding has largely been ignored. ${ }^{4}$ One reason may be that bradycardia during hypotensive haemorrhagic shock is documented only as casuistic reports ${ }^{5-8}$ where relative bradycardia has led to diagnostic difficulty.

Intensive care medicine provides the opportunity for systematic observations of heart rate during hypotension due to haemorrhage. We have analysed the recordings of heart rate and blood pressure of 20 consecutive patients who presented in haemorrhagic shock. To evaluate the effects of oxygen tension on heart rate during shock arterial blood samples were obtained in five patients. Pancreatic polypeptide, a hormone under vagal control, '9 was also measured in five patients. In these patients also arginine vasopressin concentrations in plasma were measured in order to evaluate the relevance of increased concentrations to the decrease in heart rate ${ }^{10}$ and pallor of patients in shock. ${ }^{11}$

\section{Patients and methods}

We collected data on consecutive patients who presented with symptoms of shock, including hypotension due to haemorrhage. During the study period 12 men and eight women (one of whom died) came to our attention. The mean (SEM) loss of blood was $2 \cdot 3(0.3) 1$, corresponding to $36(4) \%$ of their estimated total mean blood volume (see table). Haemorrhage occurred from internal as well as external lesions. The patients were initially treated 